\title{
The altered profile of a donated cadaver population: challenges for teaching and research?
}

\author{
Desiré M. Brits, Brendon K. Billings, Beverley Kramer, Erin F. Hutchinson
}

School of Anatomical Sciences, Faculty of Health Sciences, University of the Witwatersrand, Johannesburg, South Africa

\section{SUMMARY}

Efforts by anatomists over the recent past, have converted the cadaver population in a South African institution from a predominantly unclaimed population into one purely derived from donors. Concurrent with this transformation were noticeable changes in cadaver demographics, which raised concerns for aspects of teaching and research. The aim of this study was therefore to explore the effects of donation on the demographics and anatomical integrity of the School's 2017 cadaver population. The provenance, ancestry, sex and age of 74 cadavers were investigated. Dissected cadavers were studied to ascertain the general condition of their anatomy. Variations in tissue integrity, morphology and overt pathologies were surveyed. Cadavers represented only one population group with slightly more females $(54 \%)$. The majority of the cohort (62\%) was aged between 71 and 90 years. With regards to anatomical integrity, $60 \%$ of the cadavers presented with adhering fascia, but no significant differences in the quantity of fat were found across the sample. High levels of muscle tearing and atrophy (76\%) oc-

Corresponding author: Professor Beverley Kramer. University of the Witwatersrand, School of Anatomical Sciences, Medical School, Faculty of Health Sciences, 2193 Johannesburg, South Africa. Phone: +27825545529 .

E-mail: Beverley.kramer@wits.ac.za curred and variations in visceral anatomy were noted. Various surgical interventions and overt pathologies were also observed. The donated cadaver population differed from previous unclaimed cadaver populations in that they consisted of only White, older individuals. Variations, surgical interventions and pathologies offer staff in anatomy an opportunity to engage with more clinically-oriented teaching, as well as introducing students to the discipline of gerontology.

Key words: Donor cadaver demographics - Integrity of morphology - Research - Teaching

\section{INTRODUCTION}

"Human anatomy lives at the interface between its dependence upon high quality dead human bodies for use in teaching and research, and the need to show respect for the deceased and their families" (Jones, 2019, p. 73).

Obtaining human cadavers for the study of anatomy has suffered from the historically unethical modes of sourcing bodies (Ball, 1989; Jones and Whitaker, 2009; Winkelmann 2018). In the recent past however, the anatomical community has en-

Dissemination history. This research was presented as a podium presentation at the 47th Annual Conference of the Anatomical Society of Southern Africa (2019). Brits D, Billings BK, Kramer B, Hutchinson EF: The shifting profile of a cadaver population.

Submitted: 22 April, 2020. Accepted: 22 July, 2020. 
deavored to acquire human cadavers for dissection through ethically acceptable means such as body donation programs (Cornwall and Stringer, 2009; Jones and Whitaker, 2012). Thus, in parts of the world there has been a transition from the use of unclaimed bodies to that of donors (Cornwall and Stringer, 2009; Kramer and hutchinsomn, 2015; Winkelmann 2018; Kramer et al., 2019). However, donor programs are not in existence in all countries across the globe, and unclaimed bodies or the bodies of executed criminals are still in use (Kramer et al., 2008; Gangata et al., 2010; Habicht et al., 2018). While studies have focused on attempting to understand the factors associated with the resistance to body donation (Anyanwu et al., 2011; Anyanwu and Obikili, 2012; ArráezAybar et al., 2014; De Gama 2016; De Gama et al., 2020), there is a paucity of information in the literature that examines the consequences or challenges to teaching and research which may stem from the transition to the use of donor bodies.

While dissection remains the "gold standard" for teaching human anatomy (Moore 1998; Ellis, 2001; Pawlina and Lachman, 2004; Biasutto et al., 2006; Azer and Eizenberg, 2007; Izunya et al., 2010; Wood et al., 2010; Alexander et al., 2014; Mwachaka et al., 2016; Romero-Reverón, 2017), time for dissection has become constrained due to major changes in the medical and allied health sciences curricula (Parker, 2002; McBride and Drake, 2018). Thus there is a perceived need to obtain high quality cadavers (Jones, 2019) that demonstrate good tissue integrity and are relatively easy to dissect. In the past, slightly younger cadavers with perceived good muscle definition and little fat, few prostheses and overt pathologies were obtained in the Wits School of Anatomical Sciences (personal communication). These cadavers were mainly from unclaimed sources (Kramer and Hutchinson, 2015). These morphological parameters are seen to enable students to undertake dissection and observe relevant structures in the reduced time available.

As a result of the transition to a body donor program (Kramer et al., 2019), a shift in the cadaver profile had been observed in the School of Anatomical Sciences, University of the Witwatersrand (Wits). Changes in age, population affinity, quality and integrity of tissue, absence of specific organs and presence of pathologies, had become apparent. These changes raised concerns in terms of their impact on the teaching of general anatomy, as well as concerns related to the diversity of the extensive teaching and research collections in the Wits School. As the Wits School had transitioned from the use of unclaimed bodies to a donor program (Kramer et al., 2019), it did not wish to return to the use of unclaimed cadavers, which although legal in South Africa (NHA, 2004), is not ethical. The aim of this study was therefore to investigate the effect of a body donor program on the cadaver demographics and anatomical integrity of tissues for teaching and research in an anatomy department.

The objectives of the study were to:

Generally compare population affinity, sex distribution, and age of donated cadavers with the mainly unclaimed cadaver population of the past.

Record the morphological integrity of tissues, anatomical variations and overt pathologies in the current donated cadavers.

\section{MATERIALS AND METHODS}

Research on cadavers in the Wits School was approved by the Human Research Ethics Committee (Medical) of the University of the Witwatersrand (W-CJ-140604-1).

\section{Sample}

The Wits School receives approximately 80 donated/bequeathed bodies per year, which support approximately 1000 undergraduate and postgraduate students per year. Students registered for degrees in medicine and/or biomedical engineering participate in full body dissection over the course of the academic year, while allied health sciences students (e.g. physiotherapy, occupational therapy and dentistry) engage in region-specific dissection relevant to their profession. Furthermore, prosected cadaveric materials that are either "wet" or plastinated as well as osteological elements are used to support all undergraduate and postgraduate courses. A variety of clinical anatomy and biological anthropology research projects as well as clinical training workshops also utilize cadavers.

All bodies are embalmed using a standard formalin embalming fluid formula and procedure (Pretorius and Brune, 1992; Brenner, 2014).

A total of 74 cadavers dissected by students during the 2017 academic year, were examined for the purposes of this study. This included cadavers that were fully dissected (medical student cadavers, $n=51$ ), as well as regionally dissected (allied health sciences cadavers, $n=23$ ) cadavers. Due to the difference in dissections undertaken by the two groups, not all regions could be observed.

\section{Methods}

Data for the 2017 cadaver population were extracted from the existing cadaver records in the Wits School and included: the provenance of the cadavers, e.g. bequeathed/donated or unclaimed, population affinity, sex, age and cause of death. Individuals who had bequeathed their bodies together with next-of-kin donors were collectively categorized as "donors" for the purposes of this study.

Two senior anatomists examined the dissected cadavers to ascertain the general state of the tissues and organs, as well as to document any vari- 
Table 1. Criteria for tissue assessment

\begin{tabular}{lll}
\hline Tissue type & Classification & \multicolumn{1}{c}{ Definition } \\
\hline \multirow{2}{*}{ Fat } & Excessive & $\begin{array}{l}\text { Bony landmarks cannot be easily palpated due to a thickened layer of adipose tissue / large } \\
\text { deposits of visceral fat observed } \\
\text { Bony landmarks easily palpated with a thin layer of subcutaneous and/or visceral fat } \\
\text { Fascia }\end{array}$ \\
& Normal & Very thin layer of subcutaneous fat with almost no visceral fat \\
& Adhering & Fascia intermingled with the adjacent fat \\
& Thick & Sheath-like covering not adherent in nature \\
Muscle & Thin & Web-like covering translucent in appearance and fragile \\
& Tearing & Muscle damage or separation of fibers \\
\hline
\end{tabular}

ations or overt pathologies. As a measure of the possible effects of the ageing process on morphological integrity, certain features such as the amount of fat, nature of the fascia and muscle were included in the examination (Table 1). Muscle tearing and atrophy in combination with one another was also classified.

Major vessels were assessed for the presence or absence of tortuosity (looping, curling or any form of entanglement with adjacent blood vessels) and for obvious variations. In addition, the presence of overt pathologies associated with the blood vessels e.g. aneurysms, were also documented. The presence and absence of major nerves as well as notable variations in their anatomy were also assessed along with a brief description of their quali- ty. Obvious visceral anatomical variations or absences were recorded as well as overt pathologies.

The state of the individual's dentition was assessed, and the presence of dental prosthetic devices was noted. Skeletal elements of the cadaver were assessed for trauma, and evidence of all surgical interventions and prosthetic devices were documented.

\section{Data analysis}

Initial examination of 10 cadavers was carried out jointly by two senior anatomists to ensure consistency and standardization with regards to tissue assessment.

Qualitative statistical analyses were conducted

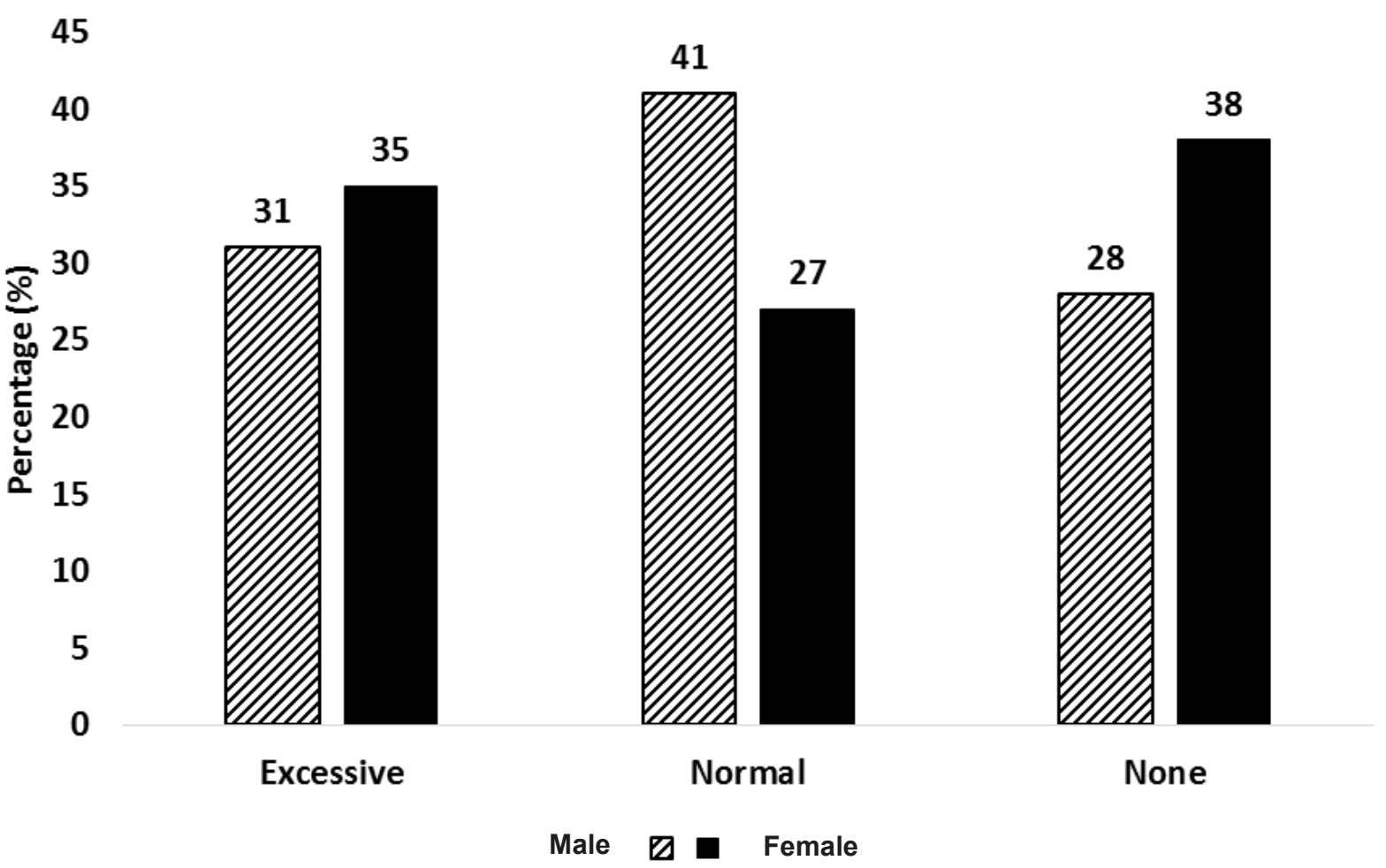

Fig 1. Percentage of male and female cadavers categorized with excessive (1), normal (2) or no (3) fat. 


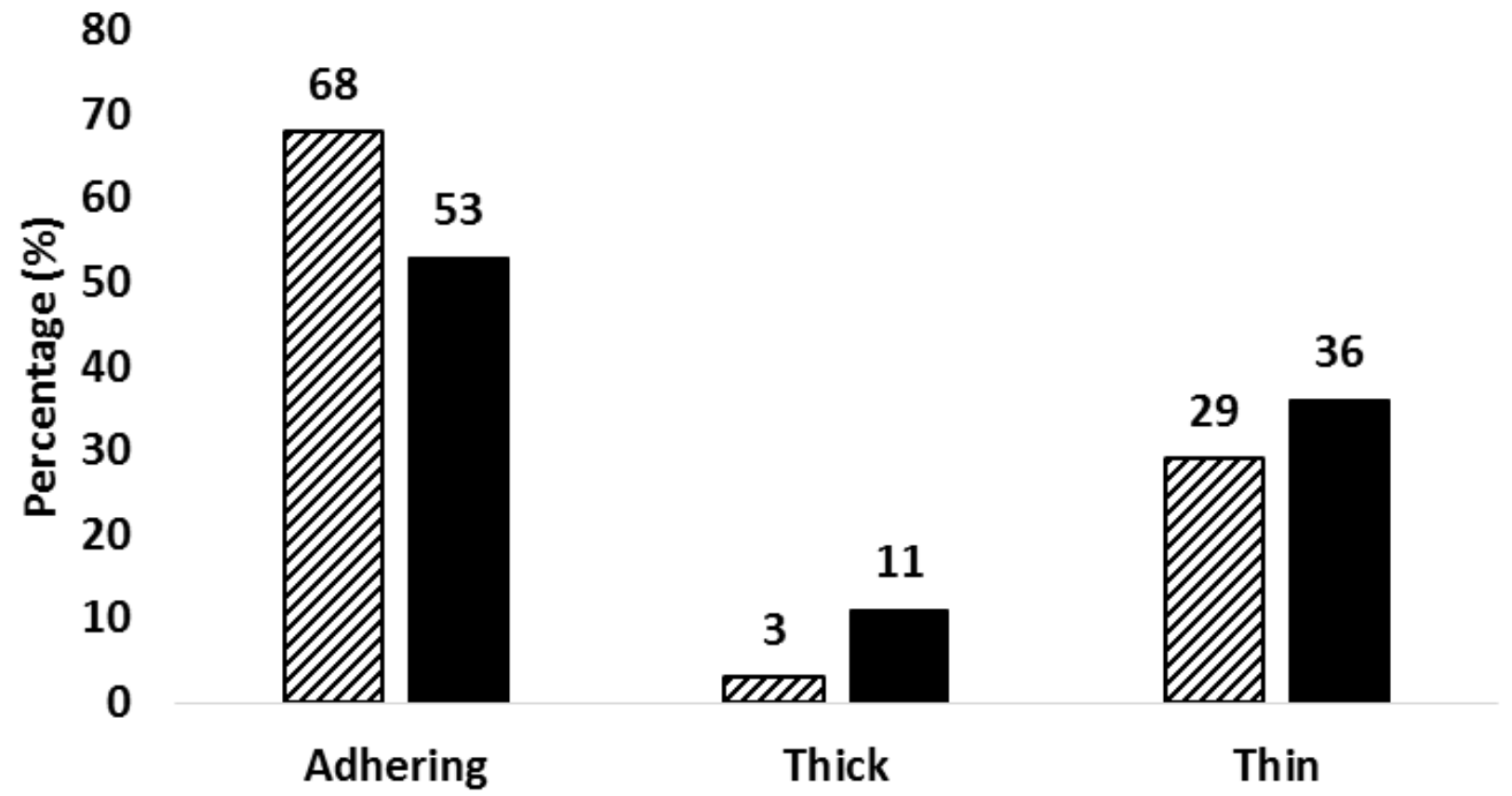

Male $\square \square$ Female

Fig 2. Percentage of male and female cadavers categorized with adhering (1), thick (2) or thin (3) fascia.

and owing to the limited sample size, the use of inferential statistical methods was restricted. Where possible, qualitative data was analyzed using a combination of frequency and contingency tables. Pearson Chi-square tests were also used to assess differences. Data analysis was conducted using SPSS v25 (IBM, Armonk, NY, USA).

\section{RESULTS}

\section{Demographic information}

The 2017 dissected cohort comprised exclusively of donated cadavers, representing only White South African individuals with an almost equal sex distribution of 39 (52.7\%) females and 35 (47.3\%) males. The sample age ranged between 29 and 100 years of age (mean $=74 \pm 13.6$ years) with the majority $(62 \%)$ of the individuals aged between 71 and 90 years of age $(n=46$; mean $=79 \pm 5.2$ years). The most commonly stated cause of death was natural causes (47\%), with other major reported causes of death including lung-related illnesses $(16 \%)$, various cancers $(11 \%)$ and heart diseases $(10 \%)$.

\section{Tissue assessment}

\section{Fat, fascia and muscles}

"Normal" fat distribution, "excessive" fat and "no" fat were equally distributed (33\%) across the sample $(n=67)$ (Fig. 1). More females showed excessive fat compared to males (Fig. 1) but this difference was not significant ( $p \leq 0.602)$.
Adhering fascia (60\%) was noted in the majority of the cadavers, followed by thin (33\%) and thick $(7 \%)$ fascia, but with no significant differences noted between the sexes ( $p \leq 0.322$ ) (Fig. 2). Adhering fascia was most frequently observed in individuals with excessive fat $(22.4 \%)$.

Muscle atrophy (78\%) and tearing (84\%) were frequently noted and most often occurred in conjunction (76\%) with one another. In females, a higher incidence of atrophy and tearing occurring together (Fig. 3) were noted (atrophy and tearing = $85 \%$ ) compared to males (atrophy and tearing = $66 \%)$.

\section{Neurovascular anatomy}

Variation in origin, branching and course of major vascular structures were observed in $42 \%$ of the cadavers, and occurred mostly in the thorax (22\%) and in the abdomen and pelvis (20\%). Significantly more vascular variations were noted in males $(p=$ 0.041 ). Tortuous vessels were identified in $37 \%$ of the cadavers, and were mainly found in the abdomen and pelvis (18.9\%).

Little variation occurred in the major nerves, such as the brachial plexus and sciatic nerves, but nerves appeared to be relatively fragile.

\section{Visceral anatomy and clinical observations}

The majority of the visceral variations were related to the heart $(n=56 ; 46 \%)$ and consisted of enlarged hearts, thickened left ventricular walls and enlarged coronary vessels. A large number of variations also occurred in the lungs $(n=56 ; 25 \%)$ and 


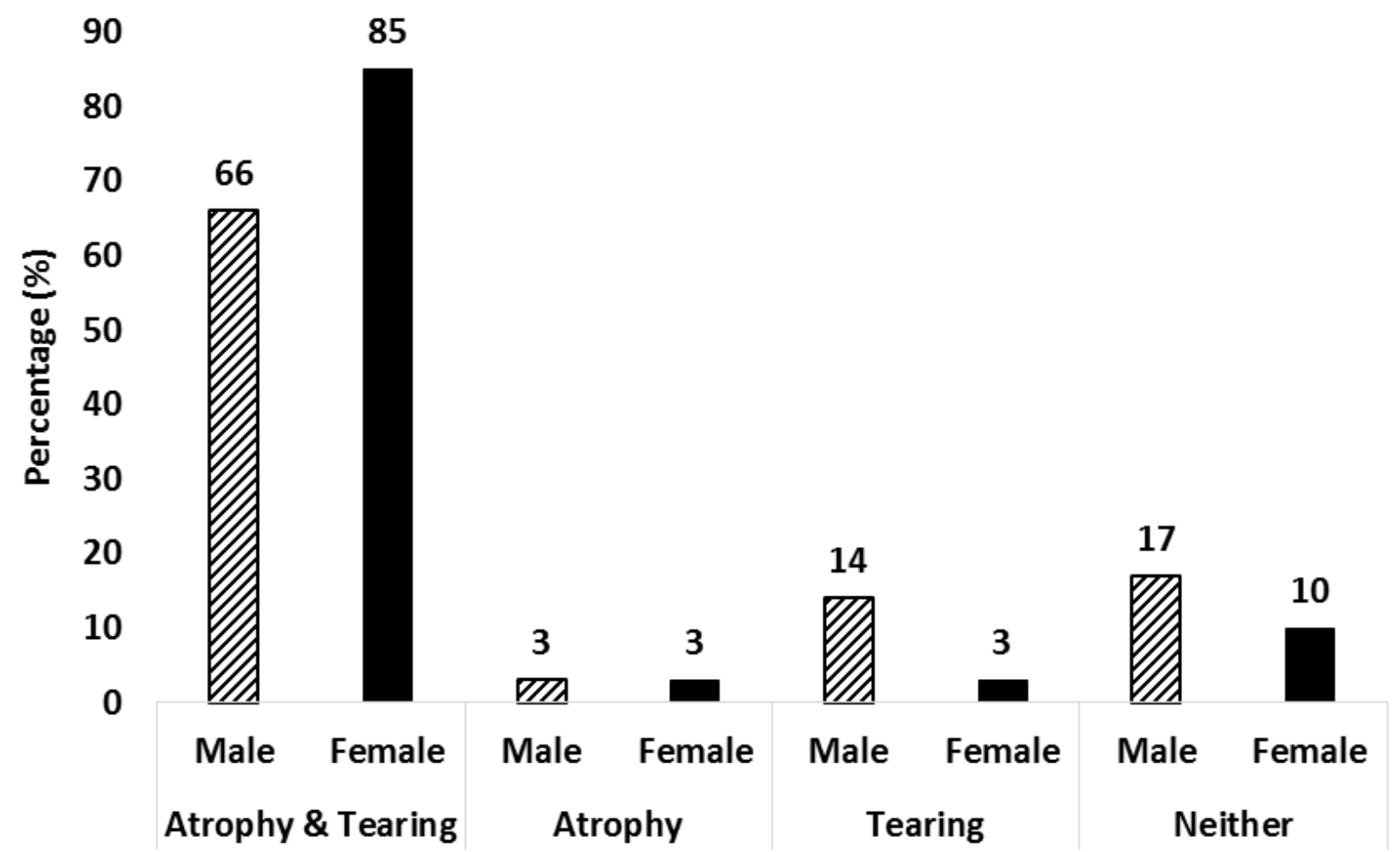

Fig 3. The percentage of muscle atrophy and tearing across the sexes.

included differences in the number of lobes and fissures. Anatomical variations related to the liver (extra lobes; $n=51 ; 6 \%$ ), pancreas (anatomical position; $n=51 ; 4 \%$ ) and kidneys (number present; $\mathrm{n}=51 ; 2 \%$ ) were noted. No variations in morphology or position were noted in relation to the stomach, small intestines and the colon. Many of the female cadavers $(54 \%)$ did not have internal reproductive organs, while only four males $(17 \%)$ had undergone a prostatectomy.

The majority of the cadaver population had a full set of the dentition (51\%; n=34) with only $22(29 \%)$ individuals presenting with either mandibular or maxillary edentulism. Of the edentulous individuals, eight males and ten females had dentures (24\%; $n=18)$.

Fractures were observed in $20 \%$ of the cadaver population and were mainly related to the thorax (ribs) (15\%). Observable bone variations and pathologies were recorded in $72 \%$ of the cadavers and included osteophytes, sternal foramina, bifid xiphoid processes and soft tissue pathologies in the abdomen and pelvis (32\%). For example, prostate and pancreatic tumors collectively occurred in $11 \%$ of cadavers.

Surgical scars were noted in $18 \%$ of cadavers, where females presented with significantly more surgeries (i.e. hysterectomies and mastectomies) compared to males $(p=0.011)$. In general, surgical scarring was mostly observed in the anterior abdominal wall $(n=74 ; 7 \%)$ and in the lower limb $(n=67 ; 8 \%)$. Hip replacements and cardiac pace- makers were infrequent.

\section{DISCUSSION}

The 2017 cadaver population in the Wits School, which was derived purely from donors, has transformed in population affinity (all are White), sex (an almost equal sex distribution occurred) and age (the majority of the cadavers were between the ages of 71 and 90). This differs from previous cadaver cohorts in the School, which were mainly unclaimed, Black African males and slightly younger in age (Kramer and Hutchinson, 2015; Kramer et al., 2019).

\section{Population affinity}

A radical change in the population affinity of the Wits cadaver population has occurred since the inception of the donor program. Between 1921 and 1993, the overwhelming majority of cadavers in the Wits School were Black African individuals, but this gradually changed to a predominantly White cadaver population between 1994 and 2013 (Kramer and Hutchinson, 2015) and finally, to an exclusively White cadaver population in 2017. The Wits School's current cadaver populations are thus not representative of the extant South African population, which comprises mainly Black African individuals $(80.7 \%)$ followed by Coloured $(8.8 \%)$, White (7.9\%) and Indian/Asian (2.6\%) population groups (Statistics South Africa, 2019). The lack of donations from Black African individuals (mainly Zulu individuals) has mainly been attributed to religious 
and cultural beliefs (De Gama et al., 2018). The consequence of acquiring cadavers from one population group only may not only affect students' exposure to a variety of humans, but it also limits the variation captured in research collections, particularly in a country such as South Africa, which has a rich multicultural diversity.

\section{Sex distribution}

The cadaver population at the Wits School, as well as other local teaching institutions (L'Abbé et al., 2005; Dayal et al., 2009; Kramer and Hutchinson, 2015; Alblas et al., 2018) and some international institutions (Hunt and Albanese, 2005; Komar and Grivas, 2008), were previously dominated by males. In South Africa this distribution was largely due to the fact that the majority of unclaimed bodies represented Black African males who were migrant workers seeking job opportunities in larger metropolitan areas (Tal and Tau, 1983; Collinson et al., 2007). Females are said to desire close family relationships and therefore prefer to work closer to home (Collinson et al., 2007; Gangata et al., 2010; Gangata, 2015; Alblas et al., 2018). This resulted in fewer unclaimed female cadavers accessioned into collections, which hampered research and teaching of the female pelvis and the associated reproductive organs (Gangata et al., 2010; EwonuBari et al., 2012; Mazyala et al., 2014; Kramer and Hutchinson, 2015). The almost equal sex distribution in the Wits 2017 cadaver population is surprising, as studies have repeatedly shown that males are more willing to donate their bodies and organs compared to females (Alashek et al., 2009; Rokade and Gaikawad, 2012; Arráez-Aybara et al., 2014).

The importance of having more females among the recent cadaver cohorts relates to the teaching of the internal reproductive organs of the female and consequent knowledge of this region, especially for those clinicians who may deal with reproductive issues in the future. The increased number of females with intact reproductive tracts will afford better representation of the sexes for both teaching and research. In addition, instead of being a challenge, hysterectomies afford a valuable teaching exposure to the relationships in the female pelvis without reproductive organs.

\section{Cause of death}

The cause of death for the majority of the donors in the Wits 2017 cadaver cohort was reported as natural. Unfortunately, this is not comparable to past cohorts due to lack of published information. Non-communicable diseases such as lung-related illness including chronic obstructive pulmonary disease (COPD) and cancers were present. This is reflective of what is seen in the general South African population, as non-communicable diseases are the major cause of death of older males and females (Statistics South Africa, 2018). The inclu- sion of cadavers who die from known causes is again of importance, as this allows the anatomy teacher to provide clinical input during dissection.

\section{Age}

The 2017 Wits cadaver population represented an older cadaver population than previously experienced (Kramer and Hutchinson, 2015), with the majority of individuals aged between 71 and 90 years of age. The shift in cadaver age may be due to the initiation of the donor program, as registration by donors in donor programs often occurs later in life (Cornwall et al., 2012). Similar patterns of an ageing cadaver population have also been noted at other local institutions, which show an underrepresentation of young individuals and an overrepresentation of the elderly (Alblas et al., 2018).

\section{Tissue assessment}

Concerns of utilization of an older cadaver cohort for teaching relate to the ability to demonstrate clear anatomical structures during dissection. Senescence may affect the anatomical integrity of the tissues observed during dissection as has been found in the current study with most of the donors showing atrophy and tearing of muscles. The high frequency of muscle atrophy and/or tearing may be associated with sarcopenia (Doherty, 2003), reduced physical activity due to an increase in age (Santilli et al., 2014), or the rigidity produced by formalin embalming. This, together with the inexperience of undergraduate dissectors, can also produce increased frequencies of muscle tearing. While muscle atrophy may be a change related to an ageing cohort of cadavers, age did not appear to have a significant impact on the fat. No significant differences were seen in relation to fat distribution in the donated cadaver population. In the past, bodies were excluded if they were deemed to be morbidly obese, but this has changed in recent years due to insufficient numbers of cadavers for teaching purposes (personal communication).

The high frequency of adhering fascia could not be associated with age, but is possibly related to embalming practices. Formalin-fixed bodies as used at Wits do not always have the desired flexibility or tissue integrity (Eisma et al., 2013; Brenner et al., 2014), as formaldehyde produces joint stiffness (Brenner et al., 2014; Balta et al., 2015), dehydrates tissues (Balta et al., 2015) and immobilizes tissue (Benkhadra et al., 2011).

\section{Neurovascular anatomy}

Vascular variations were noted in the 2017 Wits cadaver cohort, and are consistent with normal anatomical variation seen throughout the human body (Sañudo et al., 2003). The fragility of nerves noted in this study is, however, in line with age related atrophy seen in the elderly (Walter and Tsiberidou, 2019). 


\section{Age and clinical observations}

More important perhaps in relation to an ageing population are the overt pathologies, surgical interventions and prostheses which were evident. The fractured ribs and long bones that were noted are thought to be related to an increase in bone fragility brought about by age (Jilka and O'Brien, 2016). Surgical interventions such as dental prostheses (full or partial dentures), hip prostheses (replacements) and cardiac pacemakers, although noted, were infrequent. The presence of these medical appliances is expected in an ageing donor sample, and are useful in the teaching of clinical anatomy, and particularly for making students aware of the discipline of gerontology.

It is clear from the above descriptions that the purely donor-derived cadavers in the 2017 cohort in the Wits School have changed from previous unclaimed cohorts to represent older, White individuals with various neurovascular and visceral variations and overt pathologies, as well as surgical interventions. Due to the Wits Schools' decision to convert to a purely donor program, some challenges have presented such as the change in population affinity, the older individuals and the variety of variations, diseases and surgical interventions. These features can however be positively translated into more clinical and applied teaching. Having a slightly increased number of females allows for the adequate teaching of female reproductive organs, as well as the clinical outcomes of hysterectomies. The older population of cadavers should be of benefit to students in a world where the population is ageing, and provides a helpful opening to explore gerontology during undergraduate training. Thus, the ethical considerations in using donor-derived bodies for teaching and research, while altering the profile of the cadavers in this particular program, remain a priority with there being no need to revert to the use of unclaimed cadavers.

However, some of the challenges arising from the donor program, such as that of age and population affinity, are more difficult to overcome in relation to research and research collections. The older cadavers will skew the collections of the Wits School towards a senescent population. In addition, the current Wits cohort embodies only one of the four major population groups in the country. The cohort is therefore not representative of the country's population demographics, and will thus impact both teaching and research. As such, the Wits School is engaging more actively with communities that it serves, to explain, encourage and demonstrate the importance of populationrepresentative donations. Anatomists from the Wits School appear on local television and radio stations to highlight the importance of body donation, and appeal to the altruistic nature of individuals. Videos, which have aired on social media, were created in multiple indigenous languages to accommodate a diverse group of individuals representative of the SA population. The Wits School is also involved in various research studies aimed at better understanding the reluctance of individuals from various population groups to donate their bodies.

\section{Study limitations}

Not all regions of some bodies were scored, as dissection is course-specific. For example, in the case of the cadavers used by dental students, only the head, neck and thorax are dissected. In addition, the surgical or congenital etiology of variations in anatomy encountered by the observers was masked by student dissection.

\section{CONCLUSION}

The cadavers in the 2017 Wits School cohort which were derived from a purely donor source, differed from previous cadaver cohorts mainly with respect to population affinity, age and sex. The nature of the morphology of this cohort with respect to muscle atrophy and fat, overt pathologies and surgical interventions appears to be related mainly to the increased age of the cohort. The latter findings offer anatomists a positive opportunity to engage in clinical and applied anatomy teaching, as well as a gateway for students into the discipline of gerontology. The change in the cadaver demographics in relation to population affinity and age is a cause of concern for the research collections of the Wits School, which over time will no longer be representative of the demographics of the extant South African population.

In the past, slightly younger cadavers with good muscle definition, little fat and little overt pathologies (personal communication) were obtained by the Wits School through the unethical use of unclaimed bodies. While the concern that ethical practice and the use of donated cadavers would result in a compromise to the quality of the cadavers being used, due to increased age and other factors, this study shows that this is not so. If anything, the altered profile of the donated cadavers is in fact of anatomical value for learning functional and clinical anatomy, as well as gerontology. Hence the transition to an ethical platform should not be considered a trade-off, but rather be seen as an enrichment to teaching.

\section{ACKNOWLEDGEMENTS}

The authors would like to acknowledge the invaluable contribution donors make to advance research and teaching in human anatomy and related health sciences fields. We would also like to thank Mr Philip Legodi from the School of Anatomical Sciences, University of the Witwatersrand for his assistance with sourcing the cadaver demographic information, and Professor Maryna Steyn, 
Head of School, for permission to conduct the study.

\section{REFERENCES}

ALASHEK WA, EHTUISH EF, ELHABASHI A, EMBERISH W, MISHRA A (2009) Reasons for unwillingness of Libyans to donate organs after death. Libyan $\mathrm{J}$ Med, 4: 158-163.

ALBLAS A, GREYLING LM, GELDENHUYS EM (2018) Composition of the Kirsten Skeletal Collection at Stellenbosch University. S Afr J Sci, 114(1-2): 1-6.

ALEXANDER M, MARTEN M, STEWART E, SERAFIN S, ŠTRKALJ, G. (2014) Attitudes of Australian chiropractic students toward whole body donation: A crosssectional study. Anat Sci Educ, 7: 117-123.

ANYANWU GE, UDEMEZUE OO, OBIKILI EN (2011) Dark age of sourcing cadavers in developing countries: A Nigerian survey. Clin Anat, 24: 831-836.

ANYANWU EG, OBIKILI EN (2012) Dissecting the dissectors: Knowledge, attitude, and practice of body bequests by Nigerian anatomists. Anat Sci Educ, 5: 347-353.

ARRÁEZ-AYBAR LA, BUENO-LÓPEZ JL, MOXHAM BJ (2014) Anatomists' views on human body dissection and donation: An international survey. Ann Anat, 196: 376-386.

AZER SA, EIZENBERG N (2007) Do we need dissection in an integrated problem-based learning medical course? Perceptions of first- and second-year students. Surg Radiol Anat, 29: 173-180.

BALL H (1928) The Body Snatchers: Doctors, Grave robbers and the Law. Reprint 1989. Dorset Press, New York.

BALTA JY, CRONIN M, CRYAN JF, O'MAHONY SM (2015) Human preservation techniques in anatomy: A 21st century medical education perspective. Clin Anat, 28: 725-734.

BIASUTTO SN, CAUSS LI, DEL RÍO LEC (2006) Teaching anatomy: Cadavers vs. computers? Ann Anat, 188: 187-190.

BENKHADRA M, GÉRARD J, GENELOT D, TROUILLOUD $P$, GIRARD $C$, ANDERHUBER $F$, FEIGL G (2011) Is Thiel's embalming method widely known? A world survey about its use. Surg Radiol Anat, 33: 359-363.

BRENNER E (2014) Human body preservation - old and new techniques. J Anat, 224: 316-344.

COLLINSON MA, TOLLMAN SM, KAHN K (2007) Migration, settlement change and health in postapartheid South Africa: Triangulating health and demographic surveillance with national census data. Scand J Public Healt, 35 Supl 69: 77-84.

CORNWALL J, STRINGER MD (2009) The wider importance of cadavers: Educational and research diversity from a body bequest program. Anat Sci Educ, 2: 234-237.

CORNWALL J, PERRY GF, LOUW G, STRINGER MD (2012) Who donates their body to science? An international, multicenter, prospective study. Anat Sci Educ,
5: 208-216.

DAYAL MR, KEGLEY AD, ŠTRKALJ G, BIDMOS MA, KUYKENDALL KL (2009) The history and composition of the Raymond A. Dart Collection of human skeletons at the University of the Witwatersrand, Johannesburg, South Africa. Am J Phys Anthropol, 140(2): 324-335.

DE GAMA BZ (2016) Cultural and religious attitudes of Black African citizens on body donation [doctoral thesis]. Durban (South Africa), University of KwaZulu Natal.

DE GAMA BZ, BHENGU TT, SATYAPAL KS (2018) Attitudes of undergraduate South African students towards body donation. Int J Morphol, 36(1): 130-134.

DE GAMA BZ, JONES DG, BHENGU TT, SATYAPAL KS (2020) Cultural practices of the Zulu ethnic group on the body and their influence on body donation. Anat Sci Educ, doi: 10.1002/ase.1950. [Epub ahead of print].

DOHERTY TJ (2003) Invited review: Aging and sarcopenia. J Appl Physiol, 95(4): 1717-1727.

EISMA R, LAMB C, SOAMES RW (2013) From formalin to Thiel embalming: what changes? One anatomy department's experiences. Clin Anat, 26(5): 564-571.

ELLIS $H$ (2001) Teaching in the dissecting room. Clin Anat, 14: 149-151.

EWONUBARI EB, WATSON JT, AMAZA DS, MADUEKE NM, DONATUS AA, EFFIONG OE (2012) Problems and prospects of acquisition of human cadaver for medical education in Nigeria. J Pak Med Assoc, 62 (11): 1134-1136.

GANGATA H (2015) A proposed worldwide classification system for ways of sourcing of anatomical cadavers that is progressive towards the use of donated anatomical cadavers. Edorium J Anat Embryol, 2: 2025.

GANGATA H, NTABA P, AKOL P, LOUW G (2010) The reliance on unclaimed cadavers for anatomical teaching by medical schools in Africa. Anat Sci Educ, 3(4): 174-183

HABICHT JL, KIESSLING C, WINKELMANN A (2018) Bodies for anatomy education in medical schools: An overview of the sources of cadavers worldwide. Acad Med, 93: 1293-1300.

HUNT DR, ALBANES J (2005) History and demographic composition of the Robert J. Terry anatomical collection. Am J Phys Anthropol, 127(4): 406-417.

IZUNYA AM, OAIKHENA GA, NWAOPARA AO (2010) Attitudes to cadaver dissection in a Nigerian medical school. Asian J Med Sci, 2: 89-94.

JILKA RL, O'BRIEN CA (2016) The role of osteocytes in age-related bone loss. Curr Osteoporos Rep, 14(1): 16 -25 .

JONES DG (2019) The ethical awakening of human anatomy: Reassessing the past and envisioning a more ethical future. In: Squires K, Errickson D, Márquez-Grant N (eds). Ethical Approaches to Human Remains. Springer Nature, Switzerland. https:// doi.org/10.1007/978-3-030-32926-6_5

JONES DG, WHITAKER MI (2009) Speaking for the Dead: The Human Body in Biology and Medicine, Sec- 
ond Edition. Ashgate Publishing Ltd, Farnham, UK.

JONES DG, WHITAKER MI (2012) Anatomy's use of unclaimed bodies: Reasons against continued dependence on an ethically dubious practice. Clin Anat, 25(2): 246-254.

KRAMER B, HUTCHINSON EF (2015) Transformation of a cadaver population: Analysis of a South African cadaver program, 1921-2013. Anat Sci Educ, 8: 445551.

KRAMER B, HUTCHINSON EF, BRITS DM, BILLINGS BK (2019) Making the ethical transition in South Africa: Acquiring human bodies for training in anatomy. Anat Sci Educ, 12(3): 264-271.

KRAMER B, PATHER N, IHUNWO AO (2008) Anatomy: spotlight on Africa. Anat Sci Educ, 1(3): 111-118.

KOMAR DA, GRIVAS C (2008) Manufactured populations: What do contemporary refence skeletal collections represent? A comparative study using the Maxwell Museum documented collection. Am J Phys Anthropol, 137(2): 224-233.

L'ABBÉ EN, LOOTS M, MEIRING JH (2005) The Pretoria Bone Collection: A modern South African skeletal sample. HOMO, 56: 197-205.

MOORE NA (1998) To dissect or not to dissect? Anat Rec (New Anat), 253(1): 8-9.

MAZYALA EJ, REVOCATUS M, MANYAMA M, MSUYA $S$, RAMBAU $P$, KIMWAGA E, MAGELLE N, MACHIMU Y, JOSHUA M, MAGORI CC (2014) Human bodies bequest program: A wake-up call to Tanzanian Medical Schools. Adv Anat, 2014: 940472.

MCBRIDE JM, DRAKE RL (2018) National survey on anatomical sciences in medical education. Anat Sci Educ, 11: 7-14.

MWACHAKA P, SAIDI H, MANDELA P (2016) Is cadaveric dissection vital in anatomy education? Perceptions of 1 st and 2nd year medical students. J Exp Clin Anat, 15(1): 14-18.

NHA (2004) National Health Act of the Republic of South Africa. Vol. 469, Cape Town, 23 July 2004, No. 26595; No 61 of 2003; Chapter 8: Control of use of blood, blood products, tissue and gametes in humans, sections 62-64. Govern Gaz 469:26595. URL: https:// www.gov.za/sites/default/files/a61-03.pdf. Accessed May 12, 2020.

PARKER LM (2002) Anatomical dissection: Why are we cutting it out? Dissection in undergraduate teaching. ANZ J Surg, 72: 910-912.

PAWLINA W, LACHMAN N (2004) Dissection in learning and teaching gross anatomy: rebuttal to McLachlan. Anat Rec B (New Anat), 281(1): 9-11.

PRETORIUS WF, BRUNE EO (1992) Introduction to anatomical techniques. University of Pretoria, South Africa.

ROKADE SA, GAIKAWAD AP (2012) Body donation in India: Social awareness, willingness and associated factors. Anat Sci Educ, 5(2): 83-89.

ROMERO-REVERÓN R (2017) Venezuelan surgeons view concerning teaching human anatomical dissection. Anat Cell Biol, 50(1): 12-16.
SANTILLI V, BERNETTI A, MANGONE M, PAOLONI M (2014) Clinical definition of sarcopenia. Clin Cases Miner Bone Metab, 11(3): 177-180.

STATISTICS SOUTH AFRICA (2018) Mortality and causes of death in South Africa, 2016: Findings from death notification 2017. Statistical release - P0309.3. Pretoria: Statistics South Africa. URL: http:// www.statssa.gov.za/publications/P03093/ P030932016.pdf

STATISTICS SOUTH AFRICA (2019) Mid-year population estimates 2019. Statistical release - P0302. Pretoria: Statistics South Africa. URL: http:// www.statssa.gov.za/publications/P0302/ P03022019.pdf

SAÑUDO JR, VÁZQUEZ R, PUERTA J (2003) Meaning and clinical interest of the anatomical variations in the 21st century. Eur J Anat, 7 Supl 1: 1-3.

TAL H, TAU S (1983) Statistical survey of the human skulls in the Raymond A. Dart collections of skeletons. S Afr J Sci, 79: 215-217.

WALTER U, TSIBERIDOU P (2019) Differential age-, gender-, and side-dependency of vagus, spinal accessory, and phrenic nerve calibers detected with precise ultrasonography measures. Muscle Nerve, 59(4): 486491.

WINKELMANN A (2018) On the way to body donation. Rev Arg de Anat Clin, 10(1): 6-8.

WOOD A, STRUTHERS K, WHITEN S, JACKSON D, HERRINGTON CS (2010) Introducing gross pathology to undergraduate medical students in the dissecting room. Anat Sci Educ, 3(2): 97-100. 